\title{
La Liga Cantábrica, una respuesta del comercio del norte peninsular al problema tarifario de los ferrocarriles y a la crisis económica de la década de 1880
}

\author{
Carlos larinaga Rodriguez ${ }^{*}$
}

\begin{abstract}
RESUMEN ABSTRACT
Siendo la cuestión tarifaria uno de los principales problemas planteados por las compañias ferroviarias españolas durante el último tercio del siglo xIx, la crisis económica de principios de la década de los ochenta agravó aún más la situación, ya que aquéllas, deseosas de mantener sus beneficios, no dudaron en recurrir una vez más a las combinaciones de tarifas. Esta vez los más perjudicados fueron los puertos cantábricos, los cuales, para salvar sus intereses y reactivar el comercio, se organizaron en la llamada Liga Cantábrica.

PALABRAS CLAVE

Norte de España, Liga Cantábrica,

Tarifas ferroviarias, comercio.

As the tariff question had been one of the main problems created by the Spanish railway companies during the last third of XIX century, in the early XIX c. eighties the economic crisis aggravated even more the situation, because those ones did not hesitate to resort to tariff combinations, anxious to keep theirs profits. This time the damagest were the Cantabrian ports, which organized the so called the Liga Cantábrica (Cantabrian League) to save theirs interests and to reactive the commerce.

\section{KEY WORDS}

North of Spain, Cantabrian League, railway's tariffs, commerce.
\end{abstract}

* Universidad de Deusto. Becario predoctoral del Gobierno Vasco. 


\section{INTRODUCCIÓN}

Tras la grave crisis económica de 1866, el último cuarto del siglo XIX supuso, en líneas generales, una fase de expansión de las grandes compañías ferroviarias. Para Norte, compañía que nos interesa para este estudio, según datos de Tedde de Lorca, el valor de sus líneas pasó de 336,9 millones de pesetas en 1875 a 1024,9 en 1900 , de suerte que a sus primitivas líneas de Madrid-Irún y Alar-Santander se incorporaron otras tales como Zaragoza-Pamplona-Barcelona, Tudela-Bilbao, AsturiasGalicia-León y Almansa-Valencia-Tarragona. También según Pedro Tedde, "la absorción de nuevas líneas entre 1875 y 1884 influyó en la mejoría de los resultados de la explotación de Norte», permitiendo una obtención de beneficios que incluso llegaron a superar el 6\% del capital entre 1881 y $1884^{1}$. Sin duda, este hecho lo tenemos que relacionar con la fase expansiva que experimentó la economía española desde mediados de la década de 1870. En efecto, atendiendo a los datos del mismo autor, podemos observar un aumento muy importante del transporte de mercancías de la Compañía del Norte durante estos años. Mercancías ligadas predominantemente al sector primario (vinos, cereales y harinas), aunque se observa ya un incremento manifiesto en la movilización de productos generados por el sector secundario (tejidos, manufacturas, minerales, combustibles y metales, sobre todo) ${ }^{2}$. Esta estrecha relación entre las primeras y el desarrollo del transporte ferroviario hizo que la crisis agraria de los ochenta determinara que, entre 1882 y 1889 , "los incrementos anuales en los ingresos por mercancías fuer(an) mínimos, o negativos, como sucedió en los ejercicios de 1882 y 1885 " ${ }^{3}$. Aunque la crisis no fue exclusivamente agraria, sino que también afectó a otros sectores de la economía.

Centrándonos únicamente en la crisis agraria, podemos decir que ésta no se sintió en España hasta los años ochenta, un poco más tarde que en otros lugares. El arancel proteccionista de 1877 y la configuración de un mercado nacional gracias al ferrocarril pueden explicar este hecho ${ }^{4}$. Sin embargo, la formación de un mercado mundial, favorecido, sin duda, por una auténtica revolución tecnológica en el transporte marítimo, fue la causante de que en determinadas regiones, como Castilla-León y Aragón ${ }^{5}$, la crisis triguera adquiriera una especial gravedad, toda vez que a lo largo del

\footnotetext{
TEDDE DE LORCA (1978), pág.139.

Ibidem, ANEs (1978) y GÓMEZ Mendoza (1984, 1985 y 1989).

TEDdE DE LORCA (1978), pág. 145 y cuadro IV-33.

Gómez Mendoza (1982), Garrabou y Sanz (1985) y Gehr (1988).

GEHR (1988) y GERMAN y FORCADELL (1988).
} 
siglo XIX habían basado su especialización en este cultivo. La roturación de nuevas tierras en países como Rusia, Estados Unidos, Argentina, India, Canadá o Australia provocó una abundante y barata producción triguera, que los modernos medios de transporte se encargaron de canalizar a los distintos mercados europeos a precios muy competitivos ${ }^{6}$. Como bien ha afirmado el profesor Garrabou,

“la drástica reduccción de las ventas en los mercados del litoral, principal destino de los abundantes excedentes de estas regiones, se tradujo en una disminución del tráfico de granos y harinas, en la aparición de stocks y almacenamientos en las zonas productoras y en un descenso de las cotizaciones» ${ }^{7}$.

Las malas cosechas de 1882 y 1883 hicieron que se tuviera que recurrir al trigo foráneo, hecho que se repetiría a lo largo de la década en las zonas costeras por la baratura del mismo, provocando la situación descrita por Ramón Garrabou.

Con el objeto de estudiar la naturaleza multiforme de la crisis, el GEHR ha mantenido la hipótesis de que mientras los gastos se registraban al alza, los precios se mantuvieron, lográndose un beneficio que podía desaparecer en el momento en que se produjera una caída de los mismos, tal como sucedió. Así, pese a que los precios de los trigos castellano-leoneses declinaron, éstos no pudieron competir con los de los cereales importados, de suerte que las tierras menos productivas fueron abandonadas y se buscó la alternativa en otros cultivos. Esta medida no terminó de solucionar el problema y pronto los productores de cereal españoles optaron por la protección del mercado nacional.

Pero no todos los cultivos se vieron afectados por la crisis 0 , al menos, no en la misma medida. De todos ellos el que más nos interesa es el vino, que en estos años vivió, según Teresa Carnero, "una auténtica edad de oro". Efectivamente, entre 1875 y 1885 se dio un aumento en la superficie plantada de viñedos y el incremento de la producción se mantuvo hasta comienzos de la década de $1890^{8}$. Sin duda, la plaga de filoxera que asoló las vides francesas desde los años sesenta favoreció la exportación de vino español. Los acuerdos comerciales con Francia beneficiaron la entrada de los vinos nacionales en el país vecino mediante una rebaja en los derechos de entrada. Esta situación se prolongó hasta principios de los 
noventa, momento en que, recuperados los viñedos de la citada plaga, Francia denunció el tratado comercial vigente, coincidiendo, además, con la propagación de la filoxera en las cepas españolas.

Así las cosas, las expectativas creadas durante la fase expansiva del ferrocarril mencionada y la manifiesta competencia existente entre las mismas compañías hicieron que éstas recurrieran a todo tipo de medios para tratar de atraerse el mayor volumen de mercancías circulantes por sus líneas. Esto fue posible gracias a una Ley General de Ferrocarriles, la del 23 de noviembre de 1877, y a un Reglamento, el del 24 de mayo de 1878, bastante permisivos con las actuaciones de aquéllas, especialmente en algunos aspectos, tales como las tarifas, aspecto fundamental que vamos a tratar en el siguiente apartado.

\section{LA CUESTIÓN TARIFARIA Y LA COMPAÑIA DEL NORTE}

Como ya señalara Miguel Artola hace unos años, el Estado siempre mostró una especial preocupación «por hacer de las compañías concesionarias de ferrocarriles un tipo especial de empresas que, por dedicarse al servicio público, combinar(an) el carácter de sociedad capitalista orientada a un fin lucrativo, con una serie de obligaciones, derivadas del carácter de sus prestaciones", de forma que vio en el control de las tarifas «uno de los instrumentos más eficaces al servicio de esta política» 9.

El profesor Artola, en ese mismo trabajo, apuntó el fracaso del Estado en este asunto y la independencia que tuvieron aquéllas para establecer todo tipo de tarifas. Según sus palabras, "dentro del límite fijado por la tarifa legal la compañia tenía la mayor libertad para fijar tarifas especiales que se constitu(ían) de resultas de la decisión de la compañía de primar un determinado factor de transporte" ${ }^{10}$, lo que dio lugar a multitud de tarifas. Este se convirtió, sin duda, en uno de los grandes problemas de la explotación ferroviaria de estos años. De hecho, en 1876, durante el segundo gobierno de Cánovas, se creó una comisión encargada del estudio de las tarifas vigentes y de sus posibles reformas. $Y$ aunque no tengamos noticia de que se llegase a formular un informe o dictamen, sus trabajos sirvieron para recoger una serie de encuestas entre instituciones públicas de carácter económico de todo el país y abrir un debate que se prolongó durante muchos años.

ARTOLA (1978), pág. 391

Ibidem, pág. 397. 
En concreto, la arbitrariedad en la aplicación de tarifas diferenciales permitía orientar el tráfico de mercancías hacia unas ciudades, comarcas y regiones en detrimento de otras, asi como favorecer a ciertos usuarios que podian obtener tarifas especiales a precios muy ventajosos. Esta libre aplicación podía ser aún más perjudicial en función de la coyuntura económica. Así, por ejemplo, en la crisis de principios de los ochenta una determinada combinación de tarifas podía poner en peligro el progreso económico de un área concreta. Fue lo que le sucedió precisamente a la costa cantábrica en 1881-82, cuando la compañía del Madrid-CáceresPortugal estableció una "tarifa de reexpedición marítima» que primaba el transporte de mercancías hacia Lisboa en detrimento de los puertos cantábricos. El descenso de los costes experimentado gracias al desarrollo de la navegación a vapor hizo posible que algunas compañías ferroviarias llegaran a acuerdos con varias navieras para poder ajustar los precios e introducir un elemento más de competencia mediante tarifas combinadas. Efectivamente, teniendo en cuenta que las condiciones de flete para Lisboa, Bilbao, Santander o Pasajes eran prácticamente las mismas, la competencia de la lucha mercantil radicaba en el transporte terrestre, desde el puerto de descarga al punto de consumo. De esta forma, una diferencia de transporte de las mercancías de más juego por valor de un $6 \%$ suponia un grave perjuicio para los puertos de la cornisa cantábrica estimado en un $36 \%$ de descenso de actividad ${ }^{11}$. Fijándonos en las cifras dadas por Joaquín Jamar, destacado hombre de negocios de la época afincado en San Sebastián, y que hemos recogido en la Tabla 1, se pueden observar los graves quebrantos producidos en aquellos puertos.

Tabla 1: Diferencia tarifaria entre Portugal y los puertos cantábricos

\begin{tabular}{lccc}
\hline & $\begin{array}{l}\text { De Lisboa y Oporto } \\
\text { Tarifa especial } \\
\text { M.L. } n^{\circ} 1\end{array}$ & $\begin{array}{l}\text { De Pasajes, San } \\
\text { Sebastián, Bilbao } \\
\text { o Santander. } \\
\text { Tarifas } 6 \text { y } 6 \text { bis }\end{array}$ & $\begin{array}{l}\text { Diferencias contra } \\
\text { los puertos } \\
\text { cantábricos }\end{array}$ \\
\hline Cacao y cafés & 50 & 68,75 & 18,75 \\
Canelas & 50 & 89,50 & 39,50 \\
Azúcares brutos & 50 & 68,75 & 18,75 \\
Bacalaos & 50 & 87,50 & 37,50 \\
Cereales y harinas & 40 & 74,75 & 34,75 \\
\hline
\end{tabular}

"Véase el artículo "Alarma fundada" publicado en El Norte de Bilbao y reproducido en El Urumea, 22-mayo-1882. Consúltese igualmente Jamar (1882) y las Exposiciones de la Liga Cantábrica (1882). 
Tabla 1: Diferencia tarifaria entre Portugal y los puertos cantábricos (continuación)

\begin{tabular}{lccc}
\hline & $\begin{array}{l}\text { De Lisboa y Oporto } \\
\text { Tarifa especial } \\
\text { M.L. } n^{\circ} 1\end{array}$ & $\begin{array}{l}\text { De Pasajes, San } \\
\text { Sebastián, Bilbao } \\
\text { o Santander. } \\
\text { Tarifas 6 y 6 bis }\end{array}$ & $\begin{array}{l}\text { Diferencias contra } \\
\text { los puertos } \\
\text { cantábricos }\end{array}$ \\
\hline $\begin{array}{l}\text { Quincalla común y loza } \\
\text { Porcelana }\end{array}$ & 50 & 89,50 & 39,50 \\
Aguardientes y espíritus & 60 & 89,50 & 29,50 \\
Cales y cementos & 60 & 75,00 & 15,00 \\
Hilazas & 30 & 45,00 & 15,00 \\
Hierros en barras & 50 & 64,50 & 14,50 \\
\hline
\end{tabular}

(*) Cifras en pesetas.

(**) Transporte de $1000 \mathrm{~kg}$. hasta Madrid.

FUENTE: J. Jamar: “La obra de la Liga», El Urumea, 7-junio-1882.

Ahora bien, aquellas plazas también tuvieron que hacer frente a la tarifación internacional impuesta por la Compañía del Norte en relación a los puertos de Burdeos y Nantes, igualmente perniciosa para sus intereses económicos, tal como puede apreciarse en la Tabla 2.

Tabla 2: Diferencia tarifaria entre Burdeos y Nantes y los puertos cantábricos establecida por la Compañía del Norte

\begin{tabular}{|c|c|c|c|}
\hline & De Burdeos & De Nantes & $\begin{array}{l}\text { De Pasajes, San Sebastián } \\
\text { Bilbao y Santander }\end{array}$ \\
\hline & Tarifa $n .918$ & 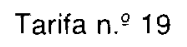 & Tarifas 6 y 6 bis \\
\hline Azúcares brutos & 199,88 & 124,83 & 275 \\
\hline Cacaos y cafés & 227,62 & 159,03 & 275 \\
\hline Canelas & 227,62 & 159,03 & 358 \\
\hline Bacalao & 199,88 & 124,83 & 350 \\
\hline Aguardientes y espiritus & 227,62 & 159,03 & 300 \\
\hline Petróleos & 199,88 & 124,83 & 250 \\
\hline Hilazas & 227,62 & 159,03 & 258 \\
\hline Cales y cementos & 199,88 & 124,83 & 180 \\
\hline Cereales y harinas & 199,88 & 124,83 & 299 \\
\hline Quincalla común & 199,88 & 124,83 & 358 \\
\hline Loza y porcelana & 227,62 & 159,03 & 358 \\
\hline Promedio por tonelada & 213 & 140 & 297 \\
\hline
\end{tabular}


Las relaciones que Norte mantenía con las compañias francesas hacían que los precios de sus tarifas combinadas crearan una situación de inferioridad a Pasajes, San Sebastián, Bilbao y Santander respecto de los puertos franceses de Burdeos y Nantes.

\section{LA ORGANIZACIÓN DE LA LIGA CANTÁBRICA}

De esta forma, y como sucediera en 1867, en que los precios absolutos de transporte ferroviario entre Madrid y Burdeos eran más reducidos que las tarifas interiores entre aquella capital y la costa cantábrica, a principios de los años ochenta los comerciantes de Vizcaya, Guipúzcoa y Santander decidieron aunar sus esfuerzos para combatir los abusos que en materia tarifaria aún persistían. Concretamente, fue una vez más Joaquín Jamar Domenech quién llevó el peso de la iniciativa.

Joaquín Jamar, a la sazón secretario de la Sociedad de Fomento del Puerto de Pasajes, fue el encargado de preparar una ponencia para la discusión del 50 tema que debía tratar el Congreso Nacional Mercantil celebrado en Madrid en diciembre de 1881. Dicho tema abordaba las cuestiones de "Tarifas, reglamentos y prácticas de los ferrocarriles en España". Teniendo en cuenta el acuerdo que se había tomado el mes anterior en París para facilitar el comercio por Lisboa por la compañía Madrid-Cáceres-Portugal, Jamar apuntó en su trabajo las reformas que debian adoptarse para el beneficio de las relaciones comerciales en España, denunciando los abusos que se daban en la aplicación de las tarifas especiales y abogando por la implantación de un precio diferencial en función de una base kilométrica. En su opinión, la tarifación especial debía referirse a mercancías de determinada naturaleza, no a su procedencia o a su dirección. Revelaba, igualmente, los defectos existentes en la reglamentación de ferrocarriles y el incumplimiento del mismo, poniendo de relieve el estado de inferioridad del individuo y del comercio frente al poder omnimodo de las compañías ferroviarias.

Esta ponencia tuvo gran calado en los sectores mercantiles vascos, vizcaíno primero y guipuzcoano después, al publicarse en forma de artículos a comienzos de 1882 en los diarios Irurac-bat de Bilbao y El Urumea de San Sebastián ${ }^{12}$. Tal es así que el 27 de marzo de ese mismo año se celebró en el Instituto de Bilbao una reunión de la "clase mercantil vizcaí-

12 Posteriormente tue incluido en su libro Liga del comercio en los puertos cantábricos publicado en Bilbao en 1882. 
na" encaminada a la creación de una Liga Comercial que tuviera por objeto tomar las medidas pertinentes para la defensa del comercio cantábrico. Como era de suponer, Joaquín Jamar fue invitado a esta asamblea y volvió a denunciar el problema tarifario y la falta de personalidad y representación del comercio en España, para lo cual propuso una organización privada y permanente del comercio español, especialmente en los puertos cantábricos, y la creación en cada plaza comercial de unas juntas más activas y emprendedoras que las existentes de Agricultura, Industria y Comercio. Así, siguiendo las bases propuestas por el propio Jamar, ese mismo día quedó constituida la "Comisión permanente de fomento y defensa del Comercio de Vizcaya" ${ }^{13}$, cuyo primer objetivo, en unión con el comercio de San Sebastián y Santander, era la reforma de la tarifación especial de los Caminos de Hierro del Norte ${ }^{14}$.

Esta iniciativa, sin embargo, no se circunscribió únicamente a Bilbao. En efecto, el 3 de abril de 1882 los representantes más importantes del comercio guipuzcoano se dirigían al presidente de la Junta de Agricultura, Industria y Comercio de la provincia solicitando su asistencia a una reunión que había de celebrar la "clase mercantil» para estudiar la grave crisis económica por la que estaba atravesando. Reunida la asamblea en el Instituto provincial el 17 de abril, fue Joaquín Jamar una vez más el encargado de tomar la palabra, animando a los asistentes, como hiciera en Bilbao, a constituir una asociación provincial, la denominada "Comisión permanente de fomento y defensa del comercio de Guipúzcoa» ${ }^{15}$, llamada a colaborar estrechamente con la de Vizcaya. En este caso, y a iniciativa del industrial Francisco Goitia, tal Comisión se comprometía no sólo a defender los intereses del comercio provincial, sino también los de las demás clases productoras ${ }^{16}$.

Constituidas ambas comisiones, esa misma primavera tuvo lugar una conferencia en Bilbao entre los delegados de ambas asociaciones. En ella

\footnotetext{
13 Presidente honorario: JOAQUIN JAMAR; presidente: LUIS BERROETA; vicepresidente: JOSE LUIS BasterRa; tesorero: Vicente URIGÜÉn; secretario: Natalicio Alonso; vocales: Fermin ARnedo, Luis Costa Vildosola, luis Zubiria, Pedro Clausen y EnRique Graves.

14 Información proporcionada por El Urumea, 30-marzo-1882, "Carta de Bilbao".

15 Presidente honorario: JOAQUIN JAMAR; presidente: NEMESIO AURPECOECHEA; vicepresidente: Ignacio Mercader; tesorero: Francisco Egaña; secretario: Angel Picavea; vocales: Joaquin lizasoain, atanasio Osacar y Cecilio Echenique. Delegados por Tolosa Francisco Goitia, por azpeitia Eusebio Gurruchaga, por Vergara Placido Zuloaga, por Irún Salustiano Olazábal y por Pasajes José A. Tutón.

16 Diario de San Sebastián, 18-abril-1882, «Reunión del comercio» y El Urumea, 18 y 19 abrit-1882, "La reunión de comerciantes" y "Dos palabras sobre la reunión del comercio", respectivamente.
} 
Jamar presentó un destacado estudio sobre tarifas internacionales, haciendo especial hincapié en la vigente entre Lisboa y Madrid, tan perjudicial para los intereses comerciales e industriales del Norte de España. Para solucionar el problema se determinó la creación de dos sub-comisiones que acudieran a Madrid para gestionar lo acordado en dicha reunión ${ }^{17}$. A decir verdad, ésta puede considerarse, en cierto modo, la asamblea constitutiva de la denominada Liga del Comercio de los puertos cantábricos, o simplemente Liga Cantábrica, a la que se añadiría, con un papel muy secundario, el puerto de Santander.

Estos representantes de la Liga Cantábrica, que partieron para la capital del reino a mediados de mayo, no sólo insistian en la diferencia tarifaria existente entre la Madrid-Cáceres y la Compañia del Norte, sino también en las deficiencias del transporte de esta última, las cuales habían llegado a tales extremos que la casa comercial bilbaína de los Sres. Urigüén, por ejemplo, se habían visto en la necesidad de valerse de carros para transportar sus mercancías al interior del país al resultarles más barato y seguro que hacerlo por ferrocarril ${ }^{18}$. Fruto de su reunión, el 23 de mayo, con los responsables de la Compañía del Norte, el Director de la misma, J. Barat, enviaba una carta el 29 de ese mismo mes a los comisionados de Bilbao, San Sebastián y Santander, expresándoles la solidaridad entre dicha compañía y el comercio de las plazas del Norte, de suerte que se determinaba una primera rebaja en el precio de las expediciones de bacalao entre Madrid y los puertos del Cantábrico (de 350 rs. por 1000 kg. a 225) y otra posterior, desde el 11 de enero de 1883, para el transporte de vino y el tráfico nacional e internacional en general, buscando la "proteccion á los productos nacionales y á los puertos cantábricos" ${ }^{19}$. En verdad, la supresión de la tarifación diferencial no se aplicó hasta el primero de junio, lo cual, sin embargo, no dejó de considerarse un éxito de la Liga Cantábrica, dada la lentitud de los trabajos de la Comisión del Ministerio de Fomento, de la que ahora daremos cuenta.

Ciertamente, la acción de la Liga Cantábrica no se limitó única y exclusivamente a negociar con la Compañía del Norte, sino que fue más allá. En su afán de que los responsables políticos intervinieran y regularan el sistema de tarifas ferroviarias, esa misma primavera enviaron unas

17 El Urumea, 3-mayo-1882 (recogido de El Norte de Bibao).

18 El Urumea, 25-mayo-1882, "Los transportes y las tarifas del Norte" (recogido de El Noticiero Bilbaino).

19 Carta reproducida por El Urumea, 2-junio-1882, "Las tarifas". Véase también el artículo de J. JAMAR «La obra de la Liga», publicado en El Urumea, 7-junio-1882. 
Exposiciones sobre reformas presentadas al Ministerio de Fomento y Presidente del Consejo de Ministros por los delegados de las Juntas de Bilbao y San Sebastián sobre reformas en materia de ferrocarriles y puertos (Madrid 1882) con el objeto de suscitar el consiguiente debate parlamentario. En ellas se ponía de manifiesto la difícil situación por la que atravesaban los puertos cantábricos como consecuencia no sólo de las medidas adoptadas por la Compañía Madrid-Cáceres-Portugal, sino también por el elevado precio de las tarifas de la Compañía del Norte. Se requería, en definitiva, una actuación inmediata del gobierno para solucionar el problema tarifario. Insistían, además, en la recuperación de los tribunales de comercio y en la delimitación de funciones de la marina mercante y de la marina de guerra como pasos importantes para revalorizar el papel del comercio en la economía del país. En consecuencia, Albareda, entonces ministro de Fomento del gobierno de Sagasta, creó por R.D. de 26 de junio una Comisión para el estudio de las reformas que debian introducirse en las tarifas y en la explotación de los ferrocarriles. Comisión que se dividiría en dos grupos con el objeto de estudiar separadamente las tarifas máximas legales por un lado y las tarifas reducidas por otro.

Cuando dicha Comisión habia iniciado ya sus trabajos tuvo lugar en Madrid el 23 de octubre una importante reunión de la Liga de Contribuyentes ${ }^{20}$. Presidida por Genaro Villanova, en representación de la Liga Cantábrica acudió Francisco Goitia, quien defendió los postulados de Joaquín Jamar frente a los ataques del insigne economista de la época Félix de Bona, para quien la aspiración del comercio de los puertos cantábricos era proteccionista e, incluso, socialista, postura que volveria a esgrimir en la colección de artículos titulada «El Estado y los Caminos de hierro", publicada en la Gaceta de los Caminos de Hierro a finales de 1882 y principios de 1883 y recogidos por entonces en un pequeño libro con el mismo título (Madrid 1883).

Estas teorias de Félix Bona no resultaban novedosas, pues ya en 1877, siendo entonces presidente de la comisión de la Sociedad Económica Matritense encargada por el gobierno de realizar un dictamen acerca del servicio y tarifas del ferrocarril, habían quedado, en buena medida, expuestas en el libro resultante del mismo titulado De la explotación y tarifas de los ferrocarriles españoles (Madrid 1877). En él Bona comparaba el sistema imperante en Inglaterra, caracterizado por la libertad total, y el de Francia, donde se daba la intervención del gobierno. Firme partidario del primero, reducía la misión de aquél únicamente a mejorar las condiciones

20 Resumen de la misma en El Urumea, 27-octubre-1882, "Liga de Contribuyentes". 
de seguridad. En su opinión, las tarifas ferroviarias españolas eran caras porque la contribución al Estado era alta, de un $15 \%$ en el traslado de viajeros, lo cual obstaculizaba el desarrollo de este medio de transporte. Con todo, el gobierno no debía intervenir en este punto, sino que debían ser las propias compañías las que tenían que regular los precios de las mismas.

Cinco años más tarde, en la colección de artículos «El Estado y los caminos de hierro", volvía a mantener unas posiciones ultraliberales, posicionándose a favor de la libertad del trabajo ("liberal e individualista") frente a la organización del trabajo por el Estado («reglamentario y proteccionista o socialista") y en pro de los "legítimos derechos" de las compañías frente a quienes, como Jamar, denunciaban los abusos impuestos por ellas. Defendía, así mismo, la estrategia comercial seguida por la compañia Madrid-Cáceres-Portugal a favor del puerto de Lisboa por el gran volumen de mercancías que éste llegaba a movilizar, de suerte que sostenía que «los beneficios que los productores obtienen por el encarecimiento artificial de sus servicios, representa una pérdida para la riqueza general, igual á la diferencia sobre el precio natural á que el servicio haría sin la intervencion de la ley proteccionista» ${ }^{21}$.

Por consiguiente, resumiendo los aspectos fundamentales de sus postulados en contra de los de la Liga Cantábrica, podemos señalar los siguientes, a saber: la completa libertad de las empresas para organizar su servicio de explotación, sin ninguna intervención del gobierno, el cual debería centrarse sólamente en la modificación de la ley de policía de los mismos; total independencia para que las compañias pudieran fijar libremente el precio de sus servicios; la supresión de los artículos del Reglamento de Ferrocarriles relativos a la ley de policía y los que tienen por objeto impedir los convenios particulares o internacionales de las compañías "para atraer transportes de puertos ó de industrias extranjeras»; y la organización de una buena policía judicial ${ }^{22}$.

Concretamente, el libro a que dio lugar estos artículos fue enviado a la Comisión nombrada por el Ministerio de Fomento para contrarrestar las reclamaciones que venía haciendo la Liga Cantábrica en la misma ${ }^{23}$. La respuesta de Joaquín Jamar tampoco se hizo esperar, ya que a finales de enero de ese mismo año de 1883 dio a la luz un breve trabajo,

21 Gaceta de los Caminos de Hierro, 31-diciembre-1882, pág. 833.

22 Gaceta de los Caminos de Hierro, 4-febrero-1883, pág. 66.

23 Es preciso decir que gracias a la influencia de la Liga de Contribuyentes de Madrid (El Dia, 4-julio-1882), el Ministerio de Fomento accedió, por R.D. de 16 de julio de ese año, a dar entrada a los representantes de la propiedad y el comercio en la Comisión. 
"Justificación de la Liga Cantábrica», en la prensa bilbaína (en el Irurac-bat y El Norte), donde rebatía los argumentos esgrimidos por Félix Bona, recomendando igualmente a la Comisión que tuviera en cuenta dicho escrito. Previamente, en octubre del año anterior había publicado unas «Notas para la Comisión informadora sobre reformas en los ferrocarriles" ${ }^{24}$ con el mismo fin y que, en cierto modo, completaban la visión dada por el diario liberal El Imparcial en un conjunto de escritos editados en los meses de agosto y septiembre, donde el articulista se mostraba partidario de la reforma de las tarifas y de la intervención del Estado ${ }^{25}$.

Por su parte, la Comisión, como denunciara igualmente Jamar, demoró mucho su dictamen, lo cual no fue óbice para que la Liga obtuviera de la Compañía del Norte buena parte de sus reivindicaciones, tal como se ha dicho más arriba. En efecto, en la Tabla 3 que presentamos a continuación puede verse la rebaja hecha por Norte en los principales ramos de tráfico, exceptuado el vino, entre los puertos cantábricos y Madrid.

Tabla 3: Rebaja tarifaria impuesta por Norte en los principales ramos de tráfico, excepto vino (junio 1883)

\begin{tabular}{lccc}
\hline \multirow{2}{*}{ Productos } & Tarifa antigua & Tarifa nueva & Rebaja por 100 kilos \\
\cline { 2 - 4 } & Rvn & Rvn & Rvn \\
\hline Azúcar bruto & 275 & 228 & 47 \\
Aguardientes & 300 & 248 & 52 \\
Arroz & 250 & 200 & 50 \\
Aceite & 250 & 224 & 26 \\
Bacalao & 350 & 224 & 126 \\
Bujias & 290 & 220 & 70 \\
Sardinas saladas & 240 & 200 & 42 \\
Carnes saladas & 240 & 208 & 32 \\
Cementos y cales & 180 & 120 & 60 \\
Maderas & 130 & 116 & 14 \\
Pastas para papel & 160 & 128 & 32 \\
Hierros forjados & 160 & 140 & 20 \\
Alambres & 160 & 120 & 40 \\
Hoja de lata & 240 & 200 & 40 \\
\hline
\end{tabular}

FUENTE: J. Jamar: “Lo que se ha hecho y lo que falta hacer, II" (EI Urumea, 4-junio-1883.

24 El Día, recopilación de los cuatro artículos en que aparecieron dichas "Notas" en el suplemento extraordinario del 22 de octubre de 1882.

25 El Imparcial, del 22 de agosto al 29 de septiembre de 1882. 
En cuanto al vino, el gran logro de la Liga fue que los precios se nivelaron tanto para la frontera como para la costa, desapareciendo las grandes diferencias que había entre un destino u otro, derivadas especialmente de la prima que favorecía la exportación por tierra, en concreto por la compañía del Midi, ligada igualmente al grupo Péreire. Así lo reflejan los datos referidos a tres importantes centros productores de vino riojanos.

Tabla 4: Rebaja tarifaria en el transporte de vino riojano ( $\mathrm{rv} / \mathrm{Tm})$

\begin{tabular}{|c|c|c|c|}
\hline & \multicolumn{2}{|c|}{ Tarifa antigua } & \multirow{2}{*}{$\frac{\text { Tarifa nueva }}{\text { Frontera-costa }}$} \\
\hline & Hendaya & Pasajes & \\
\hline Rioja & 63 & & - \\
\hline Haro & & 74 & 64 \\
\hline Briones & & 77 & 68 \\
\hline Cenicero & & 80 & 76 \\
\hline
\end{tabular}

FUENTE: J. Jamar: Carta del 19 de junio de 1883 al Irurac-bat, reproducida en El Urumea, 23junio-1883.

En esta misma carta Jamar insistía en el hecho de que si bien los precios por ferrocarril para la exportación de vino riojano a París habían subido, la vía marítima, en cambio, se había abaratado, de suerte que, según sus cálculos, resultaban menos gravosos estos envíos a través de Pasajes - Bilbao (54 ptas./tonelada) que directamente (56,50 francos).

Ahora bien, a tenor de los datos aportados por el profesor Gómez Mendoza (Tabla 5), fue Guipúzcoa la provincia que salió más beneficiada en este tráfico de vinos. En concreto, al señalar los principales mercados vinícolas de la red de Norte cifra el aumento de tonelaje de vinos experimentado por esta provincia en 7 veces entre $1878 / 80$ y $1884 / 85$, pasando su participación de un 4,5 a un 21,6 por $100^{26}$. Sin duda, esta intensificación no respondió a un aumento de la demanda interior, sino a un estímulo de la demanda exterior, principalmente francesa. Sin embargo, lo que más llama la atención es la pérdida de peso de Vizcaya, sobre todo, y, en menor medida, de Santander. Refiriéndose al puerto bilbaíno, recientemente Natividad de la Puerta ha señalado que "esta desviación probablemente tenga que ver con las mayores tarifas portuarias que habia que pagar en Bilbao, por las obras, a lo que hay que añadir que la compañia

26 Gómez Mendoza (1984), pág.88. 


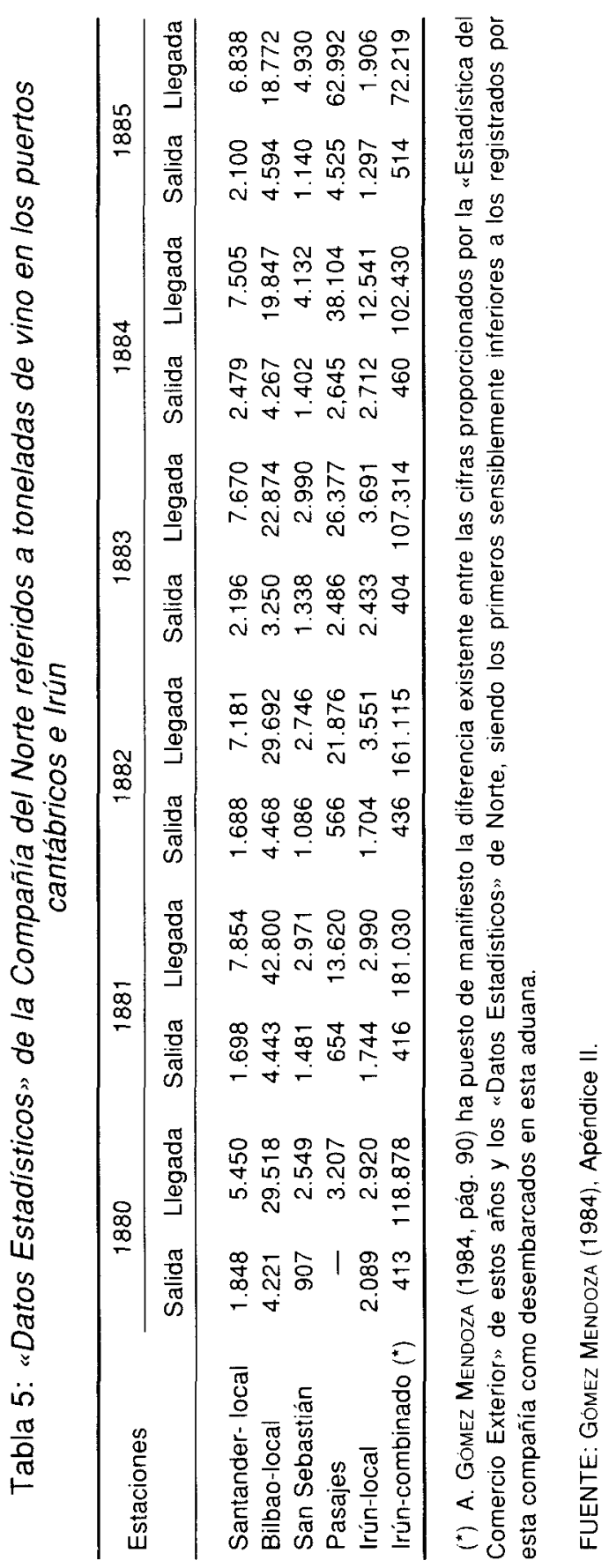


del ferrocarril Bilbao-Tudela habia sido absorbida por la Compañia de ferrocarriles del Norte" ${ }^{27}$. Tampoco debemos olvidar que, a la luz de los datos presentados por esta misma autora, los alimentos ocupaban un capítulo muy reducido dentro del tráfico comercial de dicho puerto ${ }^{28}$. Por 10 tanto, si bien es cierto que la compañía del Midi francés, como ya se ha indicado, debió ejercer una gran atracción sobre los caldos españoles para ser transportados por tierra, especialmente hasta las nuevas tarifas impuestas por Norte, sin embargo, desde 1883 se produjo un descenso muy considerable del tonelaje desembarcado en la estación combinada de Irún, frente a un ascenso muy significativo de Pasajes, con vistas, sin duda, a la exportación por mar, tal como apuntaba Joaquín Jamar.

Con todo, y volviendo al tema de las tarifas, podemos terminar diciendo que, si bien la Comisión entregó su escrito en primavera de 1884, sus resoluciones no tuvieron incidencia legislativa hasta 1887. Aunque la orden del 11 de febrero de este año exigía a las compañías que diesen adecuada publicidad a sus tarifas y aplicaran la más reducida, los usuarios no quedaron satisfechos puesto que aquéllas se aprovecharon de lo que les era favorable y en muchas ocasiones consiguieron eludir las medidas que les perjudicaban o limitaban su libertad. De esta guisa, y como ya apuntara el profesor Artola, el problema tarifario se mantuvo, cuando menos, hasta comienzos de este siglo, a pesar de la importante labor desarrollada por la Liga Cantábrica que, de hecho, y como se ha visto, consiguió rebajas muy sustanciosas de la Compañía del Norte.

\section{CONCLUSIONES}

Si bien es cierto que el primer objetivo propuesto por la Liga Cantábrica fue luchar contra un sistema tarifario de ferrocarriles que consideraba injusto y hacer que el Estado interviniera en el asunto obligando a las compañias a mantener unos criterios comunes y unificadores de cumplimiento en todas ellas, también es verdad que quiso dar un paso más allá, tratando de revalorizar el papel social y económico de lo que denominaba la "clase comercial". Joaquín Jamar, que en la década de los setenta había sido socio capitalista de una empresa de maderas y tonelaje en Morcenx, Las Landas, conocía bien el funcionamiento tanto de los ferrocarriles franceses como del sistema comercial del país vecino. Profundo admirador

Puerta (1994), pág. 249.

lbidem, cap. IV. 
de lo galo, centró su campaña no sólo en el arreglo de la cuestión de las tarifas sino también en la búsqueda de fórmulas que mejorasen la actividad comercial en España y dignificaran el papel de los comerciantes dentro de la estructura económica del país. Convencido de la potente fuerza y el ancho campo que el comercio tenía en España, denunció la falta de organización de esta "clase comerciante». Así, en la reunión del comercio bilbaíno del 27 de marzo de 1882 insistió mucho en esta idea, apuntando que en Francia

“las Cámaras del comercio con su vida independiente, con sus recursos propios, con la elevada tutela que ejercen sobre los intereses colectivos de las clases mercantiles son un elemento que se hace escuchar en los parlamentos y se hace obedecer por los mas altos poderes" ${ }^{29}$.

En su opinión, esta falta de organización incidía en la debilidad del comercio, haciendo posible que el poder de las compañías ferroviarias fuera total. Sólo mediante la creación de unas instituciones privadas, diferenciadas de las juntas de Agricultura, Industria y Comercio, llamadas a defender los intereses de los comerciantes, se podía dar solución al problema. De ahi que propusiera, en primer lugar, la fundación de comisiones en los puertos cantábricos, en esos momentos los más afectados por las combinaciones tarifarias, aunque siempre con miras a la articulación de una estructura superior que diera cabida a todo el comercio nacional.

Para ello era preciso introducir reformas en el Código de Comercio y la Ley de Enjuiciamiento Civil vigentes, de suerte que se restablecieran los antiguos tribunales de comercio, se limitara el poder de las compañías ferroviarias, se fomentara la organización de los comerciantes en cuerpos independientes $y$, en definitiva, se diera al comercio la importancia que realmente tenía en el desarrollo económico del país.

Pese al debate intelectual que se suscitó en determinados foros y prensa especializada, como ya se ha indicado, en realidad las ideas de Jamar y de la Liga Cantábrica contaron con muy pocos apoyos. En sus reflexiones sobre "Lo que se ha hecho y lo que falta por hacer", del 6 de junio de 1883, Joaquín Jamar se lamentaba de que, con excepción de la Liga de Contribuyentes de Madrid y la Liga de Valencia, el comercio del litoral español, incluido Santander, habia "permanecido mudo" ${ }^{30}$. Esto, sin embargo, no fue un obstáculo para que la Liga consiguiera llevar al Parlamento el

El Urumea, 30-marzo-1882, "Carta de Bilbao".

El Urumea, 12-junio-1883 
problema tarifario existente e influyera en la creación de una comisión que estudiara este problema. Además de conseguir de la Compañía del Norte que modificara sus tarifas para no perjudicar la actividad comercial de los puertos del Cantábrico.

En definitiva, la Liga Cantábrica fue una toma de conciencia de los comerciantes vizcaínos y guipuzcoanos, principalmente, ante la discriminación que estaban sufriendo tanto por las compañías ferroviarias como por la Administración. Conscientes de que sólo desde la organización podían lograr la fuerza suficiente para modificar la situación, la Liga se convirtió en el órgano mercantil más importante de la época. Denunció el estado de postergación y marginación en que se hallaba el comercio español y abogó por soluciones prácticas imperantes en otras naciones, especialmente en Francia, con el fin de reactivarlo y devolverle el puesto que realmente le correspondía en la economía española. La comisión creada por el mimistro Albareda no fue sino una consecuencia directa de su actividad. Incluso, es posible que el nuevo Código de Comercio promulgado en 1885 tuviera también buena parte de sus orígenes en la campaña desarrollada por la Liga, aunque esto, evidentemente, debe ser objeto de un estudio más profundo, limitándonos nosotros aquí únicamente a apuntar una posibilidad que parece plausible.

\section{BIBLIOGRAFIA}

ANES, Rafael (1978): "Relaciones entre el ferrocarril y la economía española (1865-1935)», en ARtola, M. (dir.): Los ferrocarriles en España, 1844-1943, vol. 2, Banco de España, Madrid. (1990): “La actividad económica en la España de la Restauración», en Dominguez Ortız, A. (dir.): Historia de España, 10. La Restauración (1874-1902), Planeta, Barcelona.

ARtola, Miguel (dir.) (1978): "La acción del Estado", en IDEM (dir.): Los ferrocarriles en España, 1844-1943, vol.1, Banco de España, Madrid

BONA, Félix (1877): De la explotación y tarifas de los ferrocarriles españoles, Sociedad Económica Matritense, Madrid.

(1883): El Estado y los Caminos de hierro. La cuestión de las tarifas, Madrid.

CARNERO, Teresa (1980): Expansión vinicola y atraso agrario, Ministerio de Agricultura, Madrid (1985): "Expansión vinícola y atraso agrario, 1870-1900", en GaARABOU, R. y SANz, J. (eds.): Historia agraria de la España contemporánea, 2. Expansión y crisis (1850-1900), Critica, Barcelona.

FRAX, E. (1987): El mercado interior y los principales puertos, 1857-1920, Banco de España, Madrid.

GARRABOU, Ramón (1975): “La crisis agrària espanyola de finals del segle XIX: Una etapa del desenvolupament del capitalisme", Recerques, n15 (traducción al castellano en IDEM y SANz, J. (ed.) (1985): Historia agraria de la España contemporánea, 2. Expansión y crisis (1850-1900), Crítica, Barcelona, págs. 477-542).

(1988): "La historiografia de la crisis: resultados y nuevas perspectivas", en IDEM (ed.): La crisis agraria de fines del siglo XIX. Critica, Barcelona.

y SANZ, Jesús (1985): "La agricultura española durante el siglo XIX: ¿inmovilismo o cam. bio?", en IDEM (ed.): Historia agraria de la España contemporánea, 2. Expansión y crisis (1850-1900), Crítica, Barcelona. 
GeRmAN, LUIS y ForCADelL, Carlos (1988): "La crisis finisecular en la agricultura interior: el caso de Aragón", en Garrabou, R. (ed.): La crisis agraria de fines del siglo XIX, Crítica, Barcelona.

Gomez Mendoza, Antonio (1982): Ferrocarriles y cambio económico en España, 1855-1913, Alianza, Madrid.

(1984): Ferrocarril y mercado interior en España (1874-1913) Vol.1: Cereales, harinas y vinos, Banco de España, Madrid.

(1985): Ferrocarril y mercado interior en España (1874-1913) Vol.2: Manufacturas textiles, materias textiles, minerales, combustibles y metales, Banco de España, Madrid.

(1989): Ferrocarril, industria y mercado en la modernización de España, Espasa Calpe, Madrid.

GeHR (1988): "La crisis agrícola en Castilla la Vieja y Andalucia: los casos del trigo y del olivar", en GarRabOU, R. (ed.): La crisis agraria de fines del siglo XIX, Crítica, Barcelona.

(1884): Informe de la Comisión creada por Real Decreto de 26 de junio de 1882 para el estudio de las tarifas de ferrocarriles, Madrid.

JamAR, Joaquín (1882): Liga del Comercio en los puertos cantábricos, Bilbao.

LIGA CANTÁBRICA (1882) Exposiciones sobre reformas presentadas al Ministerio de Fomento y Presidente del Consejo de Ministros por los delegados de las Juntas de Bilbao y San Sebastián sobre reformas en materia de ferrocarriles y puertos, Madrid.

Pan-Montojo, J. (1994a): La bodega del mundo. La vid y el vino en España (1800-1936), Alianza. Madrid.

(1994b): «El vino y la política comercial en la Restauración», Agricultura y Sociedad, n. ${ }^{\circ} 72$.

Prados de la Escosura, Leandro (1988): De imperio a nación. Crecimiento y atraso económico en España, Alianza, Madrid.

PUERTA, Natividad de la (1994): El puerto de Bilbao como reflejo del desarrollo industrial de Vizcaya (1857-1913), Autoridad Portuaria de Bilbao, Bilbao.

SANZ, Jesús M. (1985): "La crisis triguera finisecular: los últimos años", en GaRCia DeLGADo, J.L. (ed.): La España de la Restauración, Siglo XXI, Madrid.

TEDDE DE LORCA, Pedro (1978): "Las compañias ferroviarias en España (1855-1935)", en ARtola, M. (dir.): Los ferrocarriles en España, 1844-1943, vol.2, Banco de España, Madrid.

TORTELLA, Gabriel (1985): "La economía española a finales del siglo XIX y principios del siglo XX», en Garcia Delgado, J.L. (ed.): La España de la Restauración, Siglo XXI, Madrid.

(1994): El desarrollo de la España contemporánea, Alianza, Madrid. 